In summary, this work suggests that a simple educational intervention can lead to significant reductions in hypnotic use. These changes appear to reduce over time and so, in order to sustain the initial impact, the educational package may need to be repeated at regular intervals and could be combined with a prescribed policy intervention, as used by Griffith \& Robinson (1996) and the audit cycle repeated.

\section{Declaration of interest}

None.

\section{Acknowledgements}

We thank Norah Foster, Directorate Lead Nurse, Martin Read, Chief Pharmacist, Elaine Jones, Pharmacist and Alison Moore, Audit Department.

\section{References}

BRITISH MEDICAL ASSOCIATION \& ROYAL PHARMACEUTICAL SOCIETY (2003) British National Formulary.
DE BURGH, S., MANT, A., MATTICK, R. P. et al (1995) A controlled trial of educational visiting to improve benzodiazepines prescribing in general practice. Australian Journal of Public Health, 19, 142-148.

DEPARTMENT OF HEALTH (2001)

National Service Framework for Older People. London: Department of Health http://www.dh.gov.uk/assetroot/ 04/07/12/83/04071283.pdf

GRIFFITH, D. \& ROBINSON, M. (1996) Prescribing practice and policy for hypnotics: a model of pharmacy audit. Age and Ageing, 25, 490-492.

GRIMLEY EVANS, J. (2003) Drugs and falls later in life. Lancet, 361, 448.

GURWITZ, J. H., FIELD, T.S., AVORN, J., et al (2000) Incidence and preventability of adverse drug events in nursing homes. American Journal of Medicine, 109, 166-168.
KALE, A. \& KALE, J. (1984) Evaluation and Treatment of Insomnia. Oxford: Oxford University Press.

LLORENTE, M. D., DAVID, D. \& GOLDEN, A. G. (2000) Defining patterns of benzodiazpines use in older adults. Journal of Geriatric Psychiatry and Neurology, 13, 150-160.

MAHOMED, R., PATON, C. \& LEE, E. (2002) Prescribing hypnotics in a mental health trust: what consultant psychiatrists say they do.

Pharmaceutical Journal, 268, 657-659. NATIONAL INSTITUTE FOR CLINICAL EXCELLENCE (2004) Guidance on the Use of Zaleplon, Zolpidem and Zopiclone for the Short-Term Management of Insomnia. Technology Appraisal Guidance 77. London: NICE. http://www.nice.org.uk/ TA077guidance

OSWALD, I. \& ADAMS, K. (1983) Get a Better Night's Sleep. London: Martin Dunitiz.

*Lucy Caswell Edward Street Hospital, Edward Street, West Bromwich, West Midlands B70 8NL, e-mail: Lucy.Caswell@smhsct.nhs.uk, Imthiaz Hoosen Lyndon Clinic, Hobbs Meadow, Solihull, West Midlands B92 8PW, Christopher A.Vassilas Queen Elizabeth Psychiatric Hospital, Edgbaston, Birmingham B15 2QZ, Sayeed Haque Queen Elizabeth Psychiatric Hospital, Edgbaston, Birmingham B15 2QZ

\title{
What's in a name? Views on psychiatric services for older people
}

\section{AIMS AND METHOD}

The aim of this study was to provide a name for a psychiatric service for older people in Dublin. A total of 296 individuals (167 doctors, 129 workshop attendees) were surveyed regarding their views on a name for the service.

\begin{abstract}
RESULTS
'Age-related psychiatry' was a universally popular term. It was chosen by $43 \%$ of general practitioners, $56 \%$ of hospital doctors and $44 \%$ of the workshop attendees, as one of their top three choices. 'Psychiatry of old age', 'geriatric psychiatry' and 'psychogeriatrics' were unpopular with all three groups.
\end{abstract}

\begin{abstract}
CLINICAL IMPLICATIONS
Names can gradually become stigmatising over time. This applies to the terms for 'old' and 'psychiatry'. In this survey all groups surveyed rejected some of the terms in widespread clinical use.
\end{abstract}

original papers may be considered stigmatising and in some instances act as barriers to care.

The Oxford dictionary describes stigma as a 'mark or sign of disgrace or discredit'. Names can be stigmatising for two reasons. First, terms used over the years to describe those with mental illness have been inherently stigmatising, such as 'mental defective'. Second, technical terms used to describe mental illness may become derogatory with time, because they describe a stigmatised group of people. The terms 'lunatic' and 'idiot', for example, were initially used as medical terms to differentiate between patients with psychiatric problems and patients with intellectual disability, but both have acquired a negative connotation over time. 
Ideally, the negative conceptualisations that people have of those with psychiatric illness could be changed over time. The Royal College of Psychiatrists' Changing

original papers
Minds Campaign aimed to reduce the stigma attached to psychiatric disorders, in order to change attitudes and behaviour towards people with mental health problems (Crisp, 2001). At present it is important to be aware that particular titles already have negative associations. Our aim was to explore current views on this matter as we wished to avoid the most stigmatising labels.

A literature search was performed to see if any previous exploration of this topic in the area of psychiatry of old age had been carried out. No relevant articles were found in the field of psychiatry.

With regard to terms used to describe older people, a study was found which had been carried out by the local geriatric medical service (O'Neill et al, 1993). In choosing a title for their service, they sought the opinions of patients, marketing managers and journalists. Patients expressed a preference for the term 'elderly'. Marketing managers preferred the term 'age-related'. Both groups rejected the term 'geriatric'. Age-Related Healthcare was the title given to this service, as it was felt to provide the most positive image. It is also worth noting that the National Council for the Elderly, a body set up in 1990 to advise the Irish government on all aspects of ageing, changed its name in 1997 to the National Council on Ageing and Older People.

\section{Method}

We conducted a survey of general practitioners (GPs) and hospital doctors referring to the service. Addresses of GPs in the greater Dublin area were obtained from hospital records and narrowed down to those practising in or just outside the catchment area. A list of doctors at all levels within the hospital was obtained and those disciplines making referrals to the service were selected.

These doctors were given 13 possible options as titles and were asked to choose the 3 titles they considered the most suitable for the service. Terms that could be chosen instead of 'psychiatry' were 'mental health' and 'psychological medicine'. The terms 'old age', 'elderly', 'agerelated', 'older people', 'geriatric' or 'later life' could be chosen in combination with these. Doctors were also invited to make any suggestions of their own. The options given are shown in Table 1.

A pilot survey was carried out on the GP trainees working in the general adult psychiatric services at that time. Following this, the survey was sent to 179 local GPs in March 2003. We attempted to minimise our response bias by sending out the survey on two separate occasions to the entire group. Accompanying this was a covering letter explaining the purpose of the survey. Hospital doctors who refer to the service were also asked to fill out their preferences using the same form.

As the study was carried out prior to commissioning the community-based service it was not possible to survey patients directly. In order to try to address this limitation we used the opportunity of a workshop on ageing and dementia to survey a group of nuns, all of whom were over 50 years of age and were either carers or had an interest in dementia. The workshop was conducted by one of us (G.S.) in conjunction with the Sisters of Mercy, Ireland, and the same options of possible titles were given to this group immediately prior to the workshop.

Table 1. Results of the survey for choosing a name for psychiatric services for older people ${ }^{1}$

\begin{tabular}{|c|c|c|c|}
\hline & GPs $(n=115)$ & Hospital doctors $(n=52)$ & Workshop attendees $(n=129)$ \\
\hline Names selected as one of top three choices & & $n(\%)$ & \\
\hline Psychiatry of old age & $16(14)$ & $9(17)$ & $5(4)$ \\
\hline Psychiatry of later life & $22(19)$ & $26(50)$ & $34(27)$ \\
\hline Psychological medicine for older people & $20(17)$ & $0 \quad(0)$ & $26(21)$ \\
\hline Psychological medicine of later life & $26(23)$ & $5(10)$ & $50(40)$ \\
\hline Psychological medicine for the elderly & $12(10)$ & $4(8)$ & $21(17)$ \\
\hline Mental health for older people & $28(24)$ & $5(10)$ & $40(32)$ \\
\hline Mental health of later life & $26(23)$ & $6(12)$ & $73(58)$ \\
\hline Age-related psychiatry & $50(43)$ & $29(56)$ & $55(44)$ \\
\hline Other suggestions: please specify & $3(3)$ & $4(8)$ & $5(4)$ \\
\hline
\end{tabular}




\section{Results}

\section{Doctors' responses}

In total 115 GPs replied, giving a response rate of $64 \%$. 'Age-related psychiatry' was the most popular term, with 50 GPs having it as one of their top three choices. 'Geriatric psychiatry', 'psychological medicine for the elderly' and 'psychiatry of old age' were unpopular. 'Agerelated psychiatry' was again the title most frequently chosen by the 52 hospital doctors who responded. 'Psychiatry of later life' and 'psychiatry for the elderly' were also very acceptable. Unpopular choices were those that included the terms 'psychological medicine' and 'mental health'. The most frequently chosen term relating to older people was 'later life'. The doctors preferred the term 'psychiatry' to the other options provided. Several people suggested that the opinions of the patients should be sought. The breakdown of results is shown in Table 1.

\section{Workshop attendees' responses}

All 129 attendees at the workshop responded. 'Mental health for later life', 'psychological medicine of later life', 'age-related psychiatry', and 'psychiatry of later life' were the most popular choices. 'Psychiatry for the elderly' and 'psychogeriatrics' were the least popular (see Table 1). Within this group, 'later life' was the most popular term relating to older people and 'mental health' was the most popular term relating to psychiatry.

\section{Discussion}

In choosing a name for a psychiatric service for older people there are two main considerations. First, the term chosen should be acceptable to service users, carers and professionals. Second, there are pragmatic issues. It must be an accurate term to describe the service provided and fit within the existing spectrum of services for older people. It must also be easy to recall and not too long. Names should not be changed for change's sake without a sound rationale.

Other disciplines within psychiatry have struggled with similar issues. For example, 'mental retardation' has been replaced by the term 'learning disability' to describe the sub-specialty within the Royal College of Psychiatrists. However, in the USA the term 'learning disability' is not synonymous with 'mental retardation' but rather with specific learning disabilities such as dyslexia. Many practitioners actually prefer the term 'intellectual disability'.

In this study, we investigated preferred terms for both 'older people' and 'psychiatry'. The term 'age-related' was the most popular with the doctors to describe 'older people' but not with the workshop attendees. This may be because the name for the local geriatric medicine service is 'age-related healthcare' and they may have chosen it because it was a term with which they were familiar. Similarly, within the hospital our service had been using the title 'psychiatry of later life', and this may explain why half of the hospital doctors had this term as one of their top three preferences. However, the group who attended the workshop were not familiar with the term 'later life', yet surprisingly rated it twice as highly as any other term to describe older people.

In contrast, doctors and workshop attendees shared a negative opinion of the term 'geriatric'. This has broader implications, as many services and organisations use this term for those over 65. This includes well-recognised journals such as the International Journal of Geriatric Psychiatry, the American Journal of Geriatric Psychiatry and International Psychogeriatrics. Also of note is the fact that all groups had poor regard for the term 'psychiatry of old age', which is used by the Irish Medical Council.

With regard to the terms for mental health, doctors preferred the term 'psychiatry', whereas workshop attendees preferred the term 'mental health', choosing 'mental health for later life' and 'psychological medicine for later life' frequently. It is interesting to note that in Ireland the term 'community psychiatric nurse' has recently been changed to 'community mental health nurse'. One-third of the responses from the workshop attendees included the term 'psychiatry'. Again, it was not the most popular term but was by no means unacceptable.

'Age-related psychiatry' and 'psychiatry of later life' were universally acceptable terms. The term 'age-related psychiatry' was ruled out for pragmatic reasons. An important consideration for us was not to be confused with the geriatric medical service in the same hospital, which is called 'age-related healthcare'. The term 'age-related' is also not specific to people over 65 years.

The next most commonly chosen term to describe this age-group was 'later life'. This suggests that at the very least it was not unpopular. The term 'psychiatry of later life' was the only term that was not found to be unacceptable by anyone. Taking all these views into account, the title 'psychiatry of later life' was chosen for this service.

No consistent 'other suggestions' emerged. This suggests that no important alternative terms have been omitted. Many of the other suggestions (from 'department for the promotion of age-related mental health' to the more interesting 'twilight care') were discarded as they were felt to be either too wordy or misleading.

In the UK the term 'old age psychiatry' is the formal designation for the specialty. In Ireland, however, the Department of Health and the Irish Medical Council use 'psychiatry of old age'. The authors believed that the terms were too similar to include them both as options.

\section{Limitations and implications}

This study is limited to an initiative in one service in Ireland. Psychiatry of old age services elsewhere should be encouraged to carry out comparable studies. It would be prudent for similar studies in the UK to use the term 'old age psychiatry' where we have used the term 'psychiatry of old age'.

As an initial study this serves to highlight currently popular terms for psychiatric services for older people. Numbers of referrers consulted relative to the population base were good and we were particularly pleased with the response rate from the GPs, which confirmed to us 
the level of support and interest for the new service and the issue studied.

It is essential to develop old age psychiatry services

original papers

conjunction with primary care services, as $95 \%$ of mental illness is managed in the community and older adults have a high GP consultation rate (Kirby \& Cooney, 1998). Although previous studies have sought GPs' views on how psychiatric services for older people should be developed (Banerjee et al, 1993; Ashaye et al, 1996; Kirby \& Cooney, 1998), none of these studies specifically addressed the issue of naming a service.

Future research should include opinions of other disciplines, colleagues from other agencies, the general public and particularly family, carers and patients. Now that the community-based service is commissioned, the opinions of patients are being explored. We eagerly await their views. It would also be interesting to repeat this survey in 10 years' time and see if our title chosen has fallen out of favour. After all, our main aim was to make our service as accessible as possible to patients and their families. As J. K. Rowling rightly wrote, 'Fear of a name increases fear of the thing itself'.

\section{Declaration of interest}

None.

\section{Acknowledgement}

We are grateful to the Sisters of Mercy, Ireland for their contribution to this study.

\section{References}

ASHAYE, O., DHADPHALE, M. \& OKORE, A. (1996) General practitioners' views of a psychogeriatric service. Psychiatric Bulletin, 20, 140-142.

BANERJEE, S., LINDESAY, J., MURPHY, E. (1993) Psychogeriatricians and general practitioners: a national survey. Psychiatric Bulletin, 17, 592-594.

CRISP, A. (2001) Changing minds: every family in the land. A campaign update. Psychiatric Bulletin, 25, 444-446.

KIRBY, M. \& COONEY, C. (1998) Setting up a new old age psychiatry service.

General practitioner views on the priorities. Psychiatric Bulletin, 22 $228-290$.

O'NEILL, D., RICE, I., WALSH, J. B., et al (1993) What's in a name? Journal of the American Geriatric Society, $\mathbf{4 1}$ (suppl.) 192.

ROWLING, J. K. (1997) Harry Potter and the Philosopher's Stone, p. 216 London: Bloomsbury Publishing. SWANWICK, G. (2002) Making progress in Ireland. Irish Psychiatric Association Bulletin, 19,22.

Psychiatric Bulletin (2006), 30, 100-102

\section{AMMA SHUWA，BRIAN FITZGERALD，CARMEN CLEMENTE AND DENNY GRANT \\ Children with learning disabilities and related needs placed out of borough: parents' perspective}

\author{
AIMS AND METHOD \\ To investigate parental experience of \\ children with learning disability \\ being placed out of borough. The \\ parents of 70 children were inter- \\ viewed.

\section{RESULTS} \\ Parents would prefer in-borough \\ provision but $90 \%$ were satisfied
}

\author{
with the current school. The main \\ problems experienced in-borough \\ were poor advice, delays, lack of \\ information and family stress. After \\ out-of-borough placement there was \\ a reported increase in the use of \\ speech and language therapy, \\ occupational therapy and sensory \\ facilities and a decrease in the use
}

of paediatric services, social services, and mental health services.

\section{CLINICAL IMPLICATIONS}

Specialist services should be helpful and reduce family burden by keeping children in-borough.
Specific psychiatric service provision for children with learning disabilities varies widely. The 1994 Audit Commission publication Seen but not Heard stated that such children have special needs and can become marginalised. It recommended a coordinated approach involving community, child health and social services. In 1997, Don't Forget Us (Mental Health Foundation, 1997) described the problems of accessing services faced by parents with children with severe learning disabilities and severe challenging behaviour. It recommended expert specialist support for these children and their families. The Government White Paper, Valuing People (Department of Health, 2001), states:
'Children with physical or learning disabilities are more vulnerable to the full range of mental health disorders and the additional social, family and emotional stresses of everyday life'.

The prevalence of psychiatric disorder in this population is 2-3 times higher than in children without learning disabilities. In 1996, Enfield \& Tonge found a prevalence of over $40 \%$ for severe emotional and behavioural disorder or psychiatric illness in 4- to 18-year-olds with learning disabilities. Less than $10 \%$ had received specialist help.

In 2002, the Assistant Director of Education in Enfield, London commissioned a review of out-ofborough placements for children with special education 